\title{
Degradation of Red Anthraquinone Dyes: Alizarin, Alizarin S and Alizarin Complexone by Ozonation
}

\author{
E. Ortiz, H. Solis, L. Noreña, and S. Loera-Serna
}

\begin{abstract}
This paper describes the degradation of red anthraquinone dyes (alizarin, alizarin $S$ and alizarin complexone) with initial concentration of $100 \mathrm{ppm}$ in aqueous solution by ozone oxidation. The results of UV/VIS and FTIR spectra showed that the anthraquinone structures, nitrogen linkages and amino groups of anthraquinone dyes were broken after the direct ozone reaction. Almost complete color removal was obtained through ozonation within about 70, 18 and $18 \mathrm{~min}$, reaction time for alizarin, alizarin $S$ and alizarin complexone, respectively. The analysis of residuals by FTIR indicated that the alizarin primary degradation products were some organic compounds (e.g., aromatic groups, carbonate esther) and $\mathrm{CO}_{3}{ }^{2-}$ (due to the dye mineralization). Alizarin $S$ degradation products exhibited IR absorption bands at 1717, 1623, 1387, 1105 and $1045 \mathrm{~cm}^{-1}$, attributed to $>\mathrm{C}=\mathrm{O}$ (carbonyl), $>\mathrm{C}=\mathrm{C}<$ (alkenes), -C-C-C (alkanes), $\mathrm{SO}_{4}{ }^{2-}$ and $-\mathrm{C}-\mathrm{O}-\mathrm{C}-$ groups respectively. Approximately $90 \%$ of alizarin can be removed from water streams with the present methodology; followed by approximately $80 \%$ removal of complexone and $70 \%$ removal of alizarin $\mathrm{S}$.
\end{abstract}

Index Terms-Anthraquinone dyes, ozonation, degradation, alizarin, alizarin $S$, alizarin complexone.

\section{INTRODUCTION}

The use of textile dyes has thrived for thousands of years and has been part of the cultural identity of many peoples. In ancient times, textiles were dyed as indication of social status; due to the high cost of most dyes, they were reserved for wealthy families. The first sources from which the dyes were obtained were plants, animals and minerals. Natural dyes show improved biodegradability and generally have a greater environmental compatibility compared to their synthetic counterparts [1]-[4]. The worldwide production of dyes is estimated to be at least of 10 million tons of dyes per year; nowadays, most of them are synthetic, used on an industrial scale, highly soluble in water, highly resistant to the action of natural agents such as sunlight, resistant to several chemical agents and washing processes and poorly biodegradable [5]. Industrial dyeing consume of the order of 120 to 180 liters of water per $\mathrm{kg}$ of product, which means the order of 43 liters per linear meter of fabric [3].

In present time, the Mexican textile industry employs directly at least $1 \%$ of the nation's economically active people, producing about 70 thousand tons of different kind of clothes, consuming about 18.5 millions of cubic meters of

Manuscript received September 9, 2016; revised November 15, 2016 This work was supported by the CONACyT under projects 154736 and 153663 .

The authors are with the Metropolitan Autonomous University, Azcapotzalco, Av. San Pablo 180, Col. Reynosa Tamaulipas, Azcapotzalco, Ciudad de México, 02200, Mexico (e-mail: mariaelbaortiz@gmail.com). water, 3.5 millions only for the dying process. About 18 Mexican states have textile industry and national production is more than 2700 millions of lineal meters of different kind of fabrics [6].

Two factors are important considering for developing better technologies for water effluent treatment: 1). The chemical stability of the dyes and 2). The huge quantity of water involved in the several processes used in this industry. In this paper we present results obtained with an advanced oxidation process for organic dyes in water effluents: ozonation, and we have selected three derivatives of antraquinone colorants because they are highly refractory to treatment procedures. Previous experiments [7]-[9], have shown ozone is able of removing dyes from water effluents, however, many times the organic content is only reduced but not eliminated.

In the present study we selected ozone as the degradation agent of dyes derivatives of anthraquinone, known for their chemical stability and the frequency of their use in the textile industry and in the laboratory: alizarin, alizarin $\mathrm{S}$ and alizarin complexone, shown in Fig. 1. We carried out the advanced oxidation of the dye molecules through ozonation since ozone is, in fact, the third strongest natural oxidant: the first is fluoride, who has a standard reduction potential $\varepsilon^{\circ}$ in aqueous solution at $25^{\circ} \mathrm{C}$ of $+2.86 \mathrm{~V}$, the second is the free hydroxyl radical $\mathrm{HO} \cdot$ with $\varepsilon^{\circ}=+2.8 \mathrm{~V}$ and then comes ozone with $\varepsilon^{\circ}=$ $+2.075 \mathrm{~V}$.

Fluoride should not be used because it is highly toxic and can modify the consistency of bones; the second, the free hydroxyl radical is in fact obtained from advanced oxidation processes, such as ozone action. Indeed, ozone in water acts as direct oxidant, however in alkaline medium reacts with water:

$$
\begin{gathered}
\mathrm{O}_{3}+\mathrm{H}_{2} \mathrm{O}+\mathrm{HO}^{-} \rightarrow \mathrm{HO}_{3}{ }^{+}+2 \mathrm{HO}^{-} \\
\mathrm{HO}_{3}{ }^{+}+\mathrm{HO}^{-} \rightarrow 2 \mathrm{HO}_{2}{ }^{-} \\
\mathrm{O}_{3}+\mathrm{HO}_{2} \rightarrow \mathrm{HO}^{-}+2 \mathrm{O}_{2}
\end{gathered}
$$

The free radicals in previous equations are strong oxidizing agents, and they are not selective [10], [11].
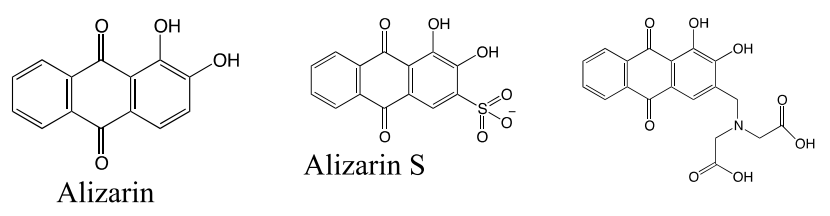

Alizarine complexon

Fig. 1. Chemical structure of red anthariquinone dyes.

The dyes from anthraquinone derivatives are the second most important class of textile dyes exhibiting a wide range 
of colors within the visible spectrum; nevertheless, they are most commonly used for purple, blue and green colors [12] Some anthraquinone derivatives can be used as acid-base indicators and as means for staining biological material. We have chosen to study these anthraquinone dyes because of their intensive use, both in industry and in the laboratory, and because their molecular structure suggests great stability.

\section{EXPERIMENTAL PROCEDURE}

\section{A. Reagents and Materials}

Alizarin, alizarin $\mathrm{S}$ and alizarin complexone anthraquinone dyes were provided by Aldrich and used with no further purification. Standard aqueous solutions containing 70 or $100 \mathrm{ppm}$ of these compounds were prepared and used in all experimental tests (Table I). The initial $\mathrm{pH}$ of the alizarin, alizarin $\mathrm{S}$ and complexone dyes was $11.23,13.00$ and 13.00, respectively, and was not adjusted during the ozonation test.

\section{B. Ozonation}

Ozone was generated from pure oxygen using an Ozone $\mathrm{O}_{3}$ Residual ${ }^{\circledR}$ Device for the current experimental work. The volumetric oxygen flow rate was kept constant and set to 0.40 liter per minute. This means that the total amount of ozone formed reaches $0.654 \mathrm{~mol} / \mathrm{h}$, which is more than that stoichiometrically required, according to the amount of dye present in the reaction mixture. The picture of the experimental reactor is depicted in Fig. 2. The glass reactor was provided with gas inlet and purge, in order to avoid pressure increases inside the reaction system since an accumulation of gas could occur. The gas-liquid reaction mixture was magnetically stirred to reduce the effect of reactant transport limitation, especially for ozone. Also, the continuous gas bubbling provokes turbulence within the reaction mixture, favoring the proximity between the two phases. Room reaction temperature was used in experimentation. Sampling was performed every 10 minutes for alizarin and every $4.5 \mathrm{~min}$ for alizarine $\mathrm{S}$ and complexone, in order to measure the amount of dye remaining by spectrophotometric analysis [13].

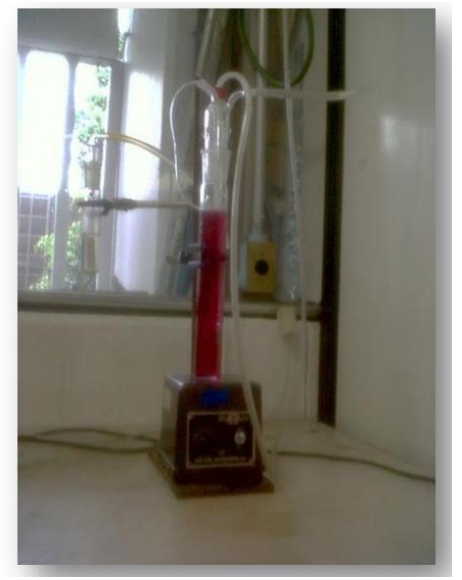

Fig. 2. Experimental device for the ozonation of anthraquinone dyes.

\section{Spectrophotometric Analysis}

The spectrophotometric analysis was carried out using a
Shimadzu Pharm Spec UV-VIS spectrometer and a Cole-Parmer FTIR spectrometer. The UV-VIS spectra of alizarin, alizarin $\mathrm{S}$ and complexone are depicted in Fig. 3. The wavelengths corresponding to a maximum absorbance of the anthraquinone dyes aqueous solutions were 529, 596 and $609 \mathrm{~nm}$ for alizarin, alizarin S and complexone, respectively. Table I presents the parameters of the calibration curves for each dye solution. Quartz cells were used for these measurements in order to avoid interferences in absorbance lectures. On the other hand, the collected samples were also dried completely by a freeze dryer system and then pressed as $\mathrm{KBr}$ pellets for acquiring their FTIR spectra. FTIR spectra $\left(4000-650 \mathrm{~cm}^{-1}\right)$ were obtained at room temperature with a 2 $\mathrm{cm}^{-1}$ resolution.
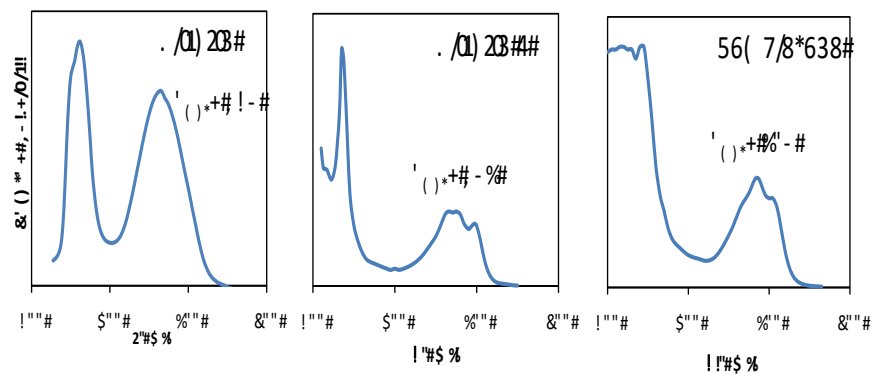

Fig. 3. UV-Vis spectra of alizarin, alizarin $\mathrm{S}$ and complexone dyes in aqueous solution at 70,100 and $100 \mathrm{ppm}$, respectively.

TABLE I: PARAMETERS OF THE CALIBRATION CURVE

\begin{tabular}{lccccc}
\hline \hline \multicolumn{1}{c}{ Dye } & $\begin{array}{c}\text { Co } \\
(\mathrm{ppm})\end{array}$ & $\lambda(\mathrm{nm})$ & Gradient & Y Intercept & $\mathrm{R}^{2}$ \\
\hline Alizarine & 70 & $\begin{array}{l}\lambda_{1}=529 \\
\lambda_{2}=325\end{array}$ & 32.72 & -0.53 & 0.994 \\
& & $\lambda_{1}=596$ & 44.82 & +0.71 & \\
Alizarine $S$ & \multirow{2}{*}{100} & $\lambda_{2}=552$ & 45.75 & -2.51 & 0.991 \\
& & $\lambda_{3}=530$ & 43.28 & -1.67 & \\
Alizarine & \multirow{2}{*}{100} & $\lambda_{1}=612$ & 36.65 & +1.10 & \\
Complexone & & $\lambda_{2}=571$ & 33.26 & +1.98 & 0.997 \\
& & $\lambda_{3}=325$ & 58.11 & -2.34 & \\
\hline \hline
\end{tabular}

\section{Analysis of Chemical Oxygen Demand}

The chemical oxygen demand (COD) analysis followed the method described in the HACH® manual, using a standard kit of oxidant reagent within the range from 20 to $150 \mathrm{mg} \mathrm{O}_{2} / \mathrm{L}$. All the samples were treated similarly and the COD analyses were performed in a calibrated $\mathrm{HACH}{ }^{\circledR}$ spectrometer model DRDL2400.

\section{RESUlTS AND DISCUSSION}

Figure 4 compares the degradation rate of alizarin, alizarin $\mathrm{S}$ and complexone, monitored through color extinction. The simplified mechanism of the ozone reaction at high $\mathrm{pH}$ is given by equation 1 . The hydroxyl $(\mathrm{OH} \bullet)$ radicals are the precursors of the decomposition of any organic substrate. These hydroxyl species oxidize anthraquinone dyes through the formation of colored and colorless intermediates, which on exposure to ozone mineralize to $\mathrm{CO}_{2}, \mathrm{H}_{2} \mathrm{O}, \mathrm{N}_{2}$ and other inorganic ions such as ammonium $\left(\mathrm{NH}_{4}{ }^{+}\right)$, nitrate $\left(\mathrm{NO}_{3}{ }^{-}\right)$and sulphate $\left(\mathrm{SO}_{4}{ }^{2-}\right)$ species [14].

$$
3 \mathrm{O}_{3}+\mathrm{H}_{2} \mathrm{O} \rightarrow 2 \mathrm{OH} \bullet+4 \mathrm{O}_{2}
$$


Each line depicting concentration vs. time in Fig. 4 adjust to a kinetic order 1 according to equation 2 . Table II presents the values of gradient, $\mathrm{Y}$ intercept and $\mathrm{R}^{2}$.

$$
\mathrm{C}=\mathrm{C}_{0} \mathrm{e}^{-\mathrm{kt}}
$$

Previous research work [13] frequently reported a kinetic order 1 for the degradation reaction of dyes with ozone. Alizarin $\mathrm{S}$ and complexone show a similar degradation rate, whereas the degradation of alizarin was slower, as indicated by the rate constant values: $\mathrm{k}=0.046 \mathrm{~min}^{-1}$ for alizarin, 0.3 $\mathrm{min}^{-1}$ for alizarin red $\mathrm{S}$ and $0.21 \mathrm{~min}^{-1}$ for complexone. The pre-exponential factor of alizarin $S$ and complexone are equal to the initial concentration, but not for alizarin. Indeed, the degradation reaction involves two reagents (dye and ozone), therefore, the expected reaction order might be 2 , however, ozone is continuously fed into the reactor, resulting in a $\mathrm{O}_{3(\mathrm{aq})}$ constant concentration with a contribution to the reaction order of zero, while the order of reaction of the dye, which degrades over time, is 1 , as observed.

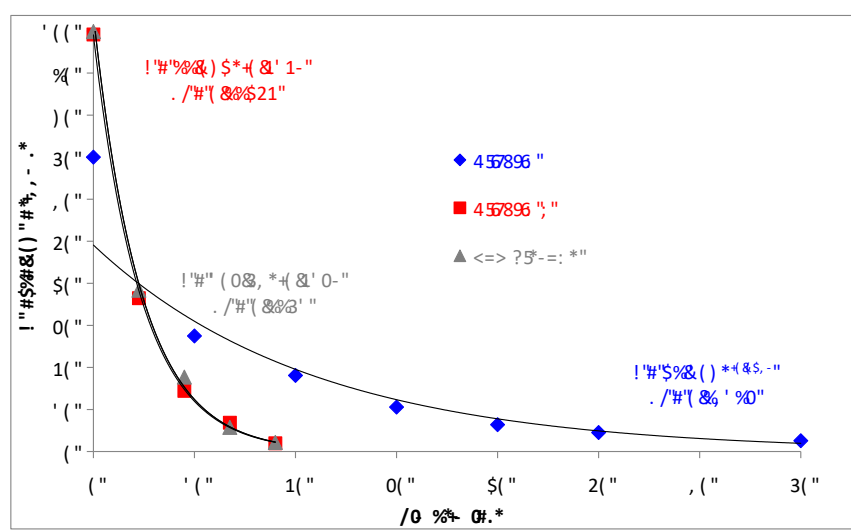

Fig. 4. Dyes oxidation progress at 529, 596 and $609 \mathrm{~nm}$ for alizarin, alizarin $\mathrm{S}$ and complexone.

Fig. 5 shows the infrared spectra of alizarin, a) before the oxidation process, b) after oxidation treatment with ozone. The spectra in Fig. 5 a) exhibit the characteristic bands of the functional group $-\mathrm{OH}$ at $3663 \mathrm{~cm}^{-1}$, attributed to water molecules and $-\mathrm{OH}$ groups present in anthraquinone molecules. Of the two $-\mathrm{OH}$ groups, at least one forms a hydrogen bond with the anthraquinone carbonyl group. The bands at $1663,1631 \mathrm{~cm}^{-1}$ are characteristic of the $>\mathrm{C}=\mathrm{O}$ functional groups present in anthraquinone molecules. In anthraquinones, carbonyl signals are shifted towards lower wavenumbers [15]. Meanwhile, the bands at 1586 and 1450 $\mathrm{cm}^{-1}$ correspond to the $>\mathrm{C}=\mathrm{C}<$ functional group, also belonging to the anthraquinone molecules. In general terms, the spectrum corresponds to the alizarin spectrum reported in the SDBS database. On the other hand, the spectrum in Fig. 5 b), no longer corresponds to alizarin; the characteristic bands of the anthraquinone molecules functional groups are not present; appears instead a band at $1625 \mathrm{~cm}^{-1}$, characteristic of aromatic groups; the bands at 1422 and $877 \mathrm{~cm}^{-1}$ correspond to $\mathrm{CO}_{3}{ }^{2-}$ produced by the mineralization dye and the bands at 1320 and $1045 \mathrm{~cm}^{-1}$ are characteristic of carbonate esther. Compared to the alizarin spectrum, the characteristic band of -OH groups has low intensity, due to the dehydration of the sample.

Fig. 6 shows the IR spectra of alizarin $S$ a) before and $b$ ) after the oxidation treatment. The alizarin $\mathrm{S}$ spectrum has a band at $3459 \mathrm{~cm}^{-1}$ corresponding to $-\mathrm{OH}$, while the bands at 3094 and $2926 \mathrm{~cm}^{-1}$ are attributed to $=\mathrm{C}-\mathrm{H}$ groups of aromatic rings. Other bands of alizarin $\mathrm{S}$ at 1666, 1634 and $1588 \mathrm{~cm}^{-1}$ are characteristic of anthraquinone molecules. Sulfonate groups present bands at 1155 and $728 \mathrm{~cm}^{-1}$. On the other hand, the spectrum in Fig. 6b, has only six bands which can be attributed as follows: $3386 \mathrm{~cm}^{-1}$ to $-\mathrm{OH} ; 1717 \mathrm{~cm}^{-1}$ to $>\mathrm{C}=\mathrm{O}$ (carbonyl); $1623 \mathrm{~cm}^{-1}$ to $>\mathrm{C}=\mathrm{C}<$ (alkenes); 1387 $\mathrm{cm}^{-1}$ to $\mathrm{C}-\mathrm{C}-\mathrm{C}$ (alkanes); $1105 \mathrm{~cm}^{-1}$ to $\mathrm{SO}_{4}{ }^{2-}$ (sulfates); 1045 $\mathrm{cm}^{-1}$ to $\mathrm{C}-\mathrm{O}-\mathrm{C}$ (esther). The presence of inorganic sulfate in the degradation product of alizarine $\mathrm{S}$ indicates the mineralization of the sample.

Fig. 7 shows the IR spectra of complexone a) before ozonation and b) after ozonation. Bands present in Fig. 7a) are attributed to the same functional groups as in the previously described dyes. Correspondence of the bands: at $3502 \mathrm{~cm}^{-1}$ to $-\mathrm{OH} ; 3014 \mathrm{~cm}^{-1}$ to $=\mathrm{C}-\mathrm{H}$ (aromatic groups); $2963 \mathrm{~cm}^{-1}$ to $\mathrm{CH}_{2} ; 1735 \mathrm{~cm}^{-1}$ to $>\mathrm{C}=\mathrm{O}$ (carboxilates), 1659 and $1634 \mathrm{~cm}^{-1}$ to $>\mathrm{C}=\mathrm{O}$ (anthraquinone); 1587 and $1507 \mathrm{~cm}^{-1}$ to $>\mathrm{C}=\mathrm{C}<$ (anthraquinone); $1037 \mathrm{~cm}^{-1}$ to $\mathrm{C}-\mathrm{N}-\mathrm{C}$ (amine ter); $899 \mathrm{~cm}^{-1}$ to $\mathrm{C}-\mathrm{O}$ (carboxyl). Complexone has four $-\mathrm{OH}$ groups, two vicinal anthraquinone and two of the free carboxyls. At least three of them may form hydrogen bonds, resulting in a very broad signal at $3502 \mathrm{~cm}^{-1}$. Anthraquinone carbonyls are displaced to lower wavenumbers (1659 and $1634 \mathrm{~cm}^{-1}$ ), while carbonyls from free acetic acid are in the expected position at $1735 \mathrm{~cm}^{-1}$.

The final products of the anthraquinone dyes ozonation reaction depend on their chemical structure. No signals of aromatic groups were present. After treating the dyes, the bands attributed to carbonyl and hydroxyl groups change their relative intensity and wavenumber, due to the transformation of the anthraquinone molecules. Evidence of inorganic ions such as carbonates, bicarbonates and sulfates was found, indicating the degree of mineralization through ozone oxidation [16].

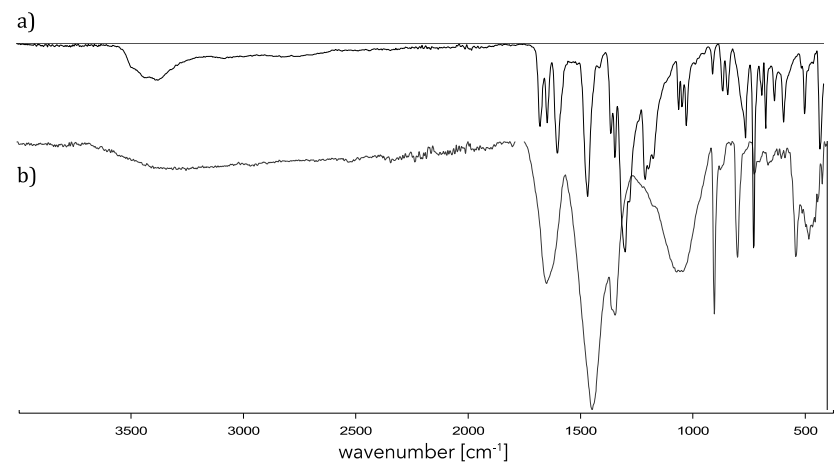

Fig. 5. FTIR spectrum of alizarin, a) before reaction, b) after oxidation process.

Concerning the residual organic molecules, the COD organic loading was determined: at the beginning $\left(\mathrm{COD}_{\mathrm{INI}}\right)$, at the end of the extinction of color $\left(\mathrm{COD}_{\mathrm{FIN}}\right)$ and after 60 $\min \left(\mathrm{COD}_{60}\right)$; the results are shown in Table II. Good percentage of degradation of the organic component was achieved by ozone oxidation, however, some compounds obtained from ozonation are more refractory to treatment 
than the original dyes. Almost $90 \%$ of alizarin was degraded, followed by approximately $80 \%$ of complexone and more than $70 \%$ of alizarin $\mathrm{S}$.

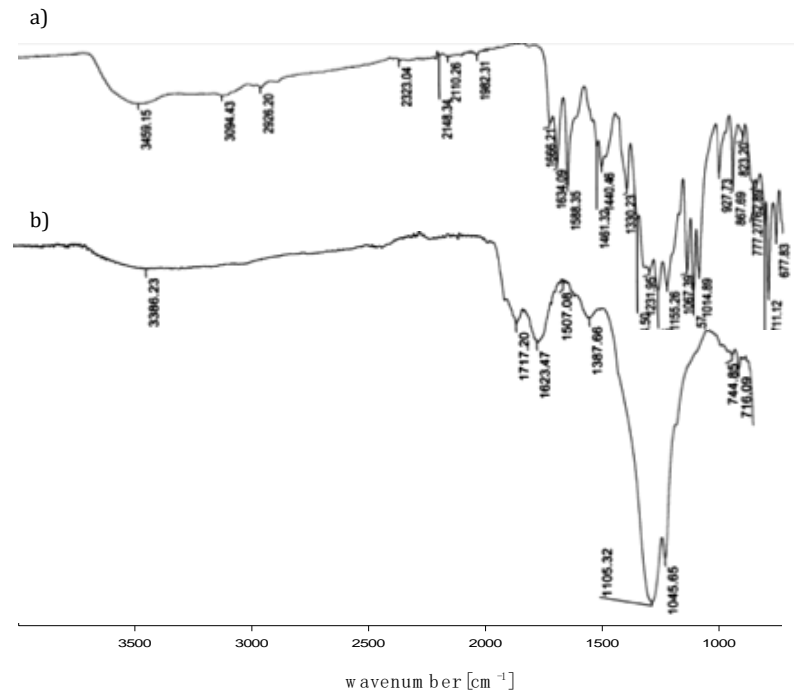

Fig. 6. FTIR spectrum of alizarin $\mathrm{S}$, a) before reaction, b) after oxidation process.

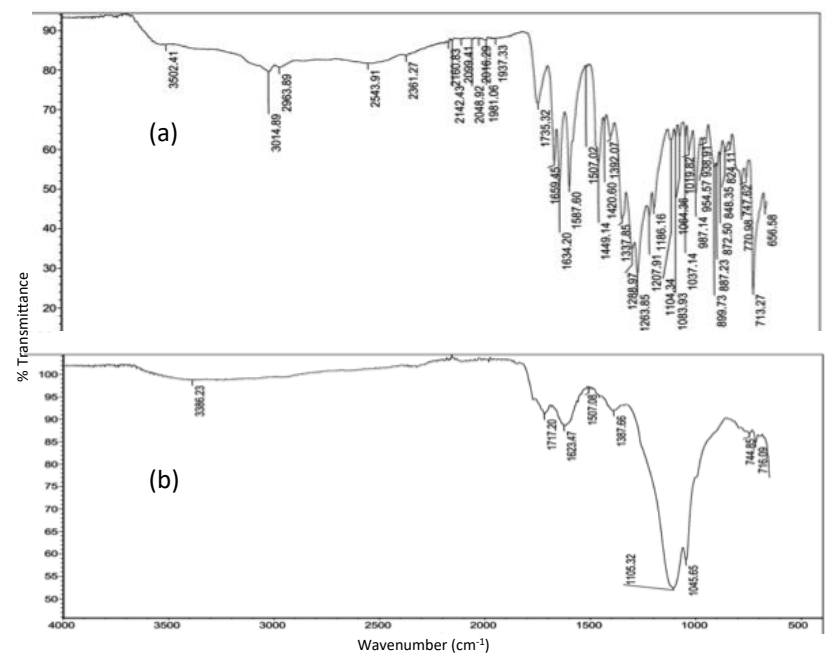

Fig. 7. FTIR spectrum of complexone, a) before reaction, b) after oxidation process.

Mechanistically, hydroxyl species oxidize the dye through the formation of colorless intermediates, which on prolonged exposure to the active oxidant agent should lead to $\mathrm{CO}_{2}, \mathrm{H}_{2} \mathrm{O}$, $\mathrm{N}_{2}$ and other inorganic ions such as ammonium $\left(\mathrm{NH}^{+}\right)$, nitrate $\left(\mathrm{NO}_{3}{ }^{-}\right)$and sulphate $\left(\mathrm{SO}_{4}{ }^{2-}\right)$ species. Although a complete color removal is observed for the oxidation process in a rather short time, only a partial degradation of the dye molecule is obtained as it can be inferred from the result of the remaining organic load. It is well known that the initial step of the degradation of a sulphonated dye (such as alizarin $\mathrm{S})$ involves the formation of harmless sulfate ions $\left(\mathrm{SO}^{2-}\right)$. These ions are formed by the cleavage of the C-S bond forming $\mathrm{SO}_{3} \cdot \bullet$, followed by the $4-3$ reaction with hydroxyl anions $\left(\mathrm{OH}^{-}\right)$. The reactions can be represented as follows[17]:

$$
\begin{aligned}
& \mathrm{R}-\mathrm{SO}_{3}{ }^{-}+\mathrm{OH} \bullet \rightarrow \mathrm{R}-\mathrm{OH}+\mathrm{SO}_{3}{ }^{-} \cdot \\
& \mathrm{SO}_{3}{ }^{-} \bullet+\mathrm{OH}^{-} \rightarrow \mathrm{OH} \bullet+\mathrm{SO}_{3}{ }^{2-}
\end{aligned}
$$

where $R$ corresponds to any alkyl or aryl group. Hence, the relative ease with which these sulfate ions are formed in the initial step is detrimental to the further breakdown of the dye structure in following reactions, such as hydroxylation, oxidation and decarboxylation. In this regard, the point of attachment of the sulfo group in the dye plays a major role.

TABLE II: RESIDUAL ORGANIC LOAD CONTENT OF THE EXPERIMENTAL DEGRADATION OF ALIZARIN, ALIZARIN S AND COMPLEXONE USING OZONATION

\begin{tabular}{llllll}
\hline \hline Dye & $\begin{array}{l}\mathrm{COD}_{\text {ini }} * \\
\mathrm{mgO}_{2} / \mathrm{L}\end{array}$ & $\begin{array}{l}\mathrm{COD}_{\text {fin }} \\
\mathrm{mgO}_{2} / \mathrm{L}\end{array}$ & $\begin{array}{l}\mathrm{COD}_{60} \\
\mathrm{mgO}_{2} / \mathrm{L}\end{array}$ & $\begin{array}{l}\% \\
\text { of } \\
\mathrm{DOC}_{\text {fin }}\end{array}$ & $\begin{array}{l}\% \\
\text { of } \\
\mathrm{DOC}_{60}\end{array}$ \\
\hline Alizarin & 146 & 82 & 15 & 43.8 & 89.7 \\
Alizarine S & 87 & 39 & 25 & 55.2 & 71.3 \\
$\begin{array}{l}\text { Alizarine } \\
\text { Complexone }\end{array}$ & 122 & 75 & 25 & 28.5 & 79.5 \\
\hline \hline
\end{tabular}

COD: chemical oxygen demand

$\mathrm{COD}_{\text {in }}$ : initial COD

$\mathrm{COD}_{\text {fin }}$ : COD after color extinction

$\mathrm{COD}_{60}$ : $\mathrm{COD}$ after $60 \mathrm{~min}$

DOC: degradation of organic compounds

$\mathrm{DOC}_{\text {fin }}$ : DOC percentage after color extinction

DOC $_{60}$ : DOC percentage after $60 \mathrm{~min}$

\section{CONCLUSIONS}

The results of the present work showed that the degradation of alizarin, alizarin $\mathrm{S}$ and complexone in aqueous solution by ozonation involved the cleavage of dye chromophore components, which was evidenced by the reduction of absorbance at 529, 596 and $609 \mathrm{~nm}$ for each dye molecule in the UV/VIS spectra. The reaction kinetic's indicates a kinetic order of 1 for all degradation reactions. The FTIR analysis of residual products from the reaction of dyes oxidation indicated that some organic compounds, such as aromatic groups, carbonate esther and $\mathrm{CO}_{3}{ }^{2-}$, were the primary degradation products, due to the mineralization of alizarin. IR bands at $1717,1623,1387,1105$ and $1045 \mathrm{~cm}^{-1}$ were attributed to $>\mathrm{C}=\mathrm{O}$ (carbonyl), $>\mathrm{C}=\mathrm{C}<$ (alkenes), -C-C-C (alkanes), $\mathrm{SO}_{4}{ }^{2-}$ and $-\mathrm{C}-\mathrm{O}-\mathrm{C}$ - groups, respectively for a alizarin $\mathrm{S}$. The percentage of degradation determined by COD indicate that some compounds obtained from ozonation are considerable more refractory to treatment than the original dyes. Best results were obtained for alizarin, since approximately $90 \%$ can be removed from water streams; followed by approximately $80 \%$ removal of complexone and $70 \%$ removal of alizarin $\mathrm{S}$.

Future work will certainly continue the study of the degradation of organic dyes widely used worldwide and present in industrial water effluents; adsorption on porous materials and catalytic advanced oxidation are among the most promising alternatives. Particular efforts should be directed at more efficient and economical processes and we intend to start focusing on the toxicological effects of organic colorants on microorganisms and living tissues, before and after water treatment.

\section{ACKNOWLEDGMENT}

We acknowledge the kind revision and amendments to this contribution done by all the reviewers as well as some of our colleagues. 


\section{REFERENCES}

[1] S. Robinson, "A history of dyed textiles: dyes, fibres, painted bark, batik, starch-resist, discharge, tie-dye, further sources for research," Studio Vista, 1969.

[2] D. Cardon, "Natural dyes: Sources, tradition, technology and science," Archetype, 2007.

[3] F. M. D. Chequer, G. A. R. Oliveira, E. R. A. Ferraz, J. Carvalho, M. V. B. Zanoni, and D. P. Oliveir, "Textile dyes: Dyeing process and environmental impact," 2013.

[4] A. Reife and H. S. Freeman, Environmental Chemistry of Dyes and Pigments, John Wiley \& Sons, 1996.

[5] K. Singh and S. Arora, "Removal of synthetic textile dyes from wastewaters: A critical review on present treatment technologies," Critical Reviews in Environmental Science and Technology, vol. 41, pp. 807-878, 2011.

[6] M. C. Rosas, "The textile and footwear industries in Mexico," Negocios ProMéxico, vol. 5, pp. 19-21, 2012.

[7] M. F. Sevimli and H. Z. Sarikaya, "Ozone treatment of textile effluents and dyes: Effect of applied ozone dose, $\mathrm{pH}$ and dye concentration," Journal of Chemical technology and Biotechnology, vol. 77, pp. 842-850, 2002.

[8] M. Constapel, M. Schellentrager, J. M. Marzinkowski, and S. Gab, "Degradation of reactive dyes in wastewater from the textile industry by ozone: analysis of the products by accurate masses," Water Res, vol. 43, pp. 733-743, 2009.

[9] K. K. Panda and A. P. Mathews, "Ozone oxidation kinetics of Reactive Blue 19 anthraquinone dye in a tubular in situ ozone generator and reactor: Modeling and sensitivity analyses," Chemical Engineering Journal, vol. 255, pp. 553-567, 2014

[10] U. V. Gunten, "Ozonation of drinking water: Part I. Oxidation kinetics and product formation," Water Research, vol. 37, pp. 1443-1467, 2003.

[11] J.-S. Chang, A. J. Kelly, and J. M. Crowley, Handbook of Electrostatic Processes, CRC Press, 1995.

[12] M. Vautier, C. Guillard, and J.-M. Herrmann, "Photocatalytic degradation of dyes in water: Case study of indigo and of indigo carmine," Journal of Catalysis, vol. 201, pp. 46-59, 2001.

[13] V. Camargo, E. Ortiz, H. Solis, C. M. Cortes-Romero, S. Loera-Serna, and C. J. Perez, "Chemical degradation of indigo potassium tetrasulfonate dye by advanced oxidation processes," Journal of Environmental Protection, vol. 5, pp. 1342-1351, 2014.

[14] R. Vinu, S. U. Akki, and G. Madras, "Investigation of dye functional group on the photocatalytic degradation of dyes by nano-TiO 2," Journal of hazardous materials, vol. 176, pp. 765-773, 2010.

[15] E. Svobodová, Z. Bosáková, M. Ohlídalová, M. Novotná, and I. Němec. "The use of infrared and Raman microspectroscopy for identification of selected red organic dyes in model colour layers of works of art," Vibrational Spectroscopy, vol. 63, pp. 380-389, 2012.

[16] T. Poznyak, P. Colindres, and I. Chairez, "Treatment of textile industrial dyes by simple ozonation with water recirculation," Journal of the Mexican Chemical Society, vol. 51, pp. 81-86, 2007.

[17] M. Rauf and S. S. Ashraf, "Fundamental principles and application of heterogeneous photocatalytic degradation of dyes in solution," Chemical engineering journal, vol. 151, pp. 10-18, 2009.

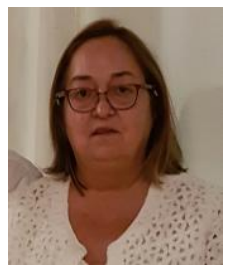

E. Ortiz got the $\mathrm{PhD}$ in chemistry teaching experience in Mexican Universities in the areas of quantum chemistry, physical chemistry, air pollution, atmospheric chemistry and environmental protection. She has tutored forty doctoral thesis, master's and bachelor's degrees. She is now recognized as a member of the National Research System level II. She has published thirty scientific papers for refereed journals internationally. Author of five books and twenty chapters of books on aerosols, emission inventory, modeling ozone, air quality in urban areas, environmental impact of fuels specialist research in the description of chemical reactivity, using mathematical models. Extensive experience in the areas of air pollution gases and airborne, atmospheric chemistry, ozone, aerosols, nuclear techniques in environmental monitoring, personal monitoring, environmental and environmental micro toxic, photochemical reactivity.

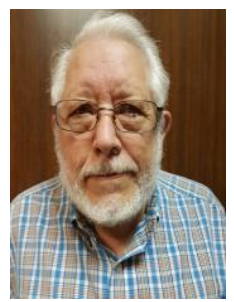

H. Solis was born in Mérida, Yucatan, Mexico on June 26, 1945. He is lecturer at the UAM-Azcapotzalco, Mexico, since 1974. He obtained her first degree in chemistry engineering (1971) from the School of Chemistry, Yucatan University. Ms. Sc. inorganic chemistry, Universidad de Guanajuato, Guanajuato, Mexico, 1975. Ph. D. sciences and engineering, environmental, Metropolitan Autonomous University, UAM-Azcapotzalco, México, 2012. Among his most outstanding works are: Nomenclatura Quimica. Hugo Solís-Correa. Editorial Patria, México. 2009. 173 pages. Chemical degradation of indigo potassium tetrasulfonate dye by advanced oxidation processes. V. Camargo, E. Ortiz, H. Solís-Correa, C. Cortés-Romero, S. Loera, C. Pérez. Journal of Environmental Protection, 2014, 5, 1342-1351. Indigo Stability: an ab initio study. H. Solis-Correa, E. Ortiz, I. Barceló, J. L. Hernández-Ávila.,. Molecular Simulation, 2011, 37(13), 1085-1090. He is a Teaching, in Chemical degradation of pollutants in aqueous medium.

Dr. Solis received the Teaching Award 1995 by the UAM- Azcapotzalco, México. Dean of Department of Basic Sciences 1999-2003 by UMA-Azcapotzalco, México.

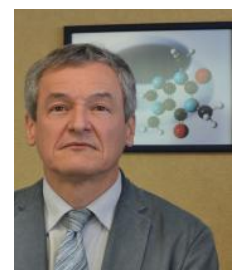

L. Noreña occupies the position of senior professor at the Department of Basic Science of the Metropolitan Autonomous University, UAM-Azcapotzalco, Mexico. He obtained her first degree in Chemical Engineering (1989) from the National Autonomous University of Mexico, and his MSc. 1993) and $\mathrm{PhD}$ (1997) degrees from the University of Manchester Institute of Science and Technology, England. From November 2007 to October 2011, he was the Head of the Department of Basic Sciences, and from May 2012 to April 2016, he was the Director of the Division of Basic Sciences and Engineering. He is a member of Mexico's National System of Researches (SNI). His current research interest includes the synthesis, characterization, and applications of porous catalytic materials and applications of polymers with electrical properties.

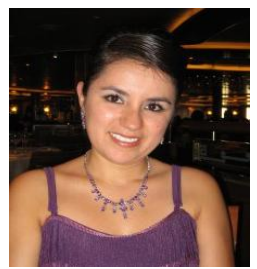

S. Loera-Serna was born in Mexico City on September 26, 1982. In 2005 she obtained her first degree in chemistry (2005) from the Metropolitan Autonomous University Iztapalapa, UAM-Iztapalapa, and her MSc (2007) and PhD (2010) degrees from the National Autonomous University of Mexico (Thesis with honors). She is senior professor at the Department of Basic Science of the Metropolitan Autonomous University Azcapotzalco, Mexico. She published 17 papers in international journals. She is a member of Mexico's National System of Researches (SNI). Her areas of research interest include design of new porous materials, adsorption, wastewater treatments and treatment of textile dyes. 